\title{
Design and preliminary test of a fluidised bed photoreactor for ethylene oxidation on mesoporous mixed $\mathrm{SiO}_{2} / \mathrm{TiO}_{2}$ nanocomposites under UV-A illumination
}

\author{
Maria Lucia V. de Chiara, ${ }^{1}$ Maria Luisa Amodio, ${ }^{1}$ Francesco Scura, ${ }^{2}$ Luigina Spremulli, ${ }^{2}$ \\ Giancarlo Colelli ${ }^{1}$ \\ ${ }^{1}$ Department of Science of Food, Agriculture and Environment, University of Foggia;
${ }^{2}$ STC srI Science, Technology \& Consulting, Mesagne (BR), Italy
}

\begin{abstract}
Ethylene $\left(\mathrm{C}_{2} \mathrm{H}_{4}\right)$ is a plant hormone that has numerous effects on many horticultural and ornamental crops. It accelerates senescence, stimulates chlorophyll loss, enhances excessive softening, promotes discoloration and browning during storage of fresh produce. Among the techniques used to remove or inhibit ethylene action during postharvest handling of fresh products (potassium-based system, high temperature catalytic oxidation, inhibition of ethylene receptors), the use of titanium oxide $\left(\mathrm{TiO}_{2}\right)$-based materials with photocatalytic activity under ultraviolet (UV) light is one of the most promising. A fluidised-bed photoreactor (FBP) was designed to decompose ethylene in the storage room atmosphere, and the relative prototype was manufactured. Since $\mathrm{TiO}_{2}$ powder alone is not suitable for use within a fluidised bed, preliminary tests to select the best support were performed. Alumina microspheres showed a good fluidisation behavior; its functionality was tested with different kind of support material and actual photocatalytic activity was tested using $\mathrm{SiO}_{2} / \mathrm{TiO}_{2}$-coated alumina microspheres. A reduction of approximately $72 \%$ of ethylene concentration in the tested $40 \mathrm{ppm}$ ethylene gas mixture was observed after $4.5 \mathrm{~h}$ of $36 \mathrm{~W}$ UV light exposure. FBP resulted to be suitable to avoid the detrimental presence of $\mathrm{C}_{2} \mathrm{H}_{4}$ in the atmosphere surrounding fresh products within cold storage rooms.
\end{abstract}

Correspondence: Maria Luisa Amodio, Department of Science of Food, Agriculture and Environment, University of Foggia, via Napoli 25, 71122 Foggia, Italy.

E-mail: marialuisa.amodio@unifg.it

Key words: ethylene reduction, fluidised bed photoreactor, postharvest stor age, titanium oxide.

Acknowledgements: the authors gratefully acknowledge funding from MIUR (Italian Ministry of University and Scientific Research) within Program PON (Project OFRALSER, Grant Agreement PON01_01435).

Received for publication: 19 August 2014.

Accepted for publication: 3 October 2014.

(C) Copyright M.L.V. de Chiara et al., 2014

Licensee PAGEPress, Italy

Journal of Agricultural Engineering 2014; XLV:435

doi:10.4081/jae.2014.435

This article is distributed under the terms of the Creative Commons Attribution Noncommercial License (by-nc 3.0) which permits any noncommercial use, distribution, and reproduction in any medium, provided the original author(s) and source are credited.

\section{Introduction}

Ethylene $\left(\mathrm{C}_{2} \mathrm{H}_{4}\right)$ is a natural plant growth substance. The presence of ethylene is not always beneficial in terms of postharvest life of whole or minimally processed fruits and vegetables. It accelerates senescence, stimulates chlorophyll loss, enhances excessive softening, stimulates sprouting, promotes abscission of leaves and flowers, stimulates phenylpropanoid metabolism, promotes discoloration and browning and hastens toughening (Saltveit, 1999). All the reported effects are not desirable during postharvest handling and should be avoided, unless ripening fastening is desired. $\mathrm{C}_{2} \mathrm{H}_{4}$ complete elimination from storage room atmosphere is the best technique to prevent its negative effects on quality of fresh produce. This can be achieved through chemical or physical methods. These methods exploit the ability of some substances or treatment to oxidise, decompose or adsorb gaseous ethylene, via different mechanisms: potassium permanganate $\left(\mathrm{KMnO}_{4}\right)$, palladium $(\mathrm{Pd})$, ethylene scrubbers by high temperature oxidation, action and synthesis inhibition, adsorption.

Equipment solutions most used in the fresh industry are based on the use of air filters which exploit the capacity of $\mathrm{KMnO}_{4}$ to oxidise ethylene via a series of reactions to acetaldehyde and acetic acid, that can be further oxidised to $\mathrm{CO}_{2}$ and $\mathrm{H}_{2} \mathrm{O}$. A further solution to reduce ethylene concentration during storage of horticultural products is represented by catalytic oxidisers: if ethylene and oxygen are combined at high temperature in the presence of a catalyst, ethylene will be oxidised. Carbon-carbon bond forming reactions in organic chemistry are facilitated by catalysis with palladium compounds; It's Fresh! sheets, using this Pd capacity, is an effective tool for removing ethylene from the atmosphere and extending storage life of fresh fruit and vegetables, as studied by Johnson Matthey scientists (Ilkenhans et al., 2007; Smith et al., 2009).

However, the reported techniques showed some disadvantages: most of them are discontinuous, expensive and/or toxic and require appropriate disposal.

One of the most recent techniques is the use of photocatalytic material to decompose ethylene under ultraviolet (UV) illumination. Titanium oxide $\left(\mathrm{TiO}_{2}\right.$ )-based materials, may represent an innovation in the postharvest field, due to its high oxidising capacity, low cost, non-toxicity, chemical robustness and high photostability. $\mathrm{TiO}_{2}$ is a material studied and used as a photocatalyst for the degradation of organic or inorganic compounds; when activated by UV light, it generates hydroxyl radicals and superoxide ions at its surface. The hydroxyl radical acts as a powerful oxidising agent to convert organic pollutants absorbed on the $\mathrm{TiO}_{2}$ catalytic surface into $\mathrm{CO}_{2}$ and water vapour (Akiyama and Togeda, 2000; Maneerat et al., 2003). Its main applications were those correlated to the use of light and a solid catalyst to degrade liquid and gas-phase pollutants (Hoffmann et al., 1995; 
Augugliaro et al., 2006; Moa et al., 2009). $\mathrm{TiO}_{2}$ presents unselectivity in oxidation reactions. Very few compounds are known that cannot be degraded by $\mathrm{TiO}_{2}$ irradiated by UV-light (Gulyas et al., 1994; Watanabe et al., 2005; Garcia-Lopez et al., 2007; Augugliaro et al., 2012).

The use of titanium oxide as a photocatalyst to decompose ethylene under UV light and at low temperature could be interesting in order to replace the commonly used ethylene removal equipments. Fluidised bed photoreactors (FBP) could represent a feasible technological solution to remove ethylene from the fruit and vegetable storage room atmosphere using photocalytic potential of $\mathrm{TiO}_{2}$. They have many advantages such as the possibility to continuously treat the polluted gaseous mixture, while having low energy requirements. Titanium oxide-based materials are suitable for use in a FBP to exert its photoxidation action against ethylene. It provides, in fact, good mixing of catalyst and pollutants, favourable $\mathrm{TiO}_{2}$ surface exposure to UV radiation due to catalyst circulation, and low mass transfer resistance (Nelson et al., 2007; Imoberdorf et al., 2008; Vega et al., 2011; Baek et al., 2013). However, $\mathrm{TiO}_{2}$ powder is classified into Geldart $\mathrm{C}$ group having a poor fluidisation behavior (Lim et al., 2000a, 2000b). It is therefore necessary to choose an UV-transparent material to support titanium oxide for its use in the reactor.

The use of fluidised beds for photocatalysts was firstly proposed and studied by Yue and Khan (1983). Experimental application has been demonstrated by Dibble and Raupp (1992) who designed a bench scale flat plate fluidised bed photoreactor for photocatalytic oxidation of trichloroethylene. More recently, Lim et al. (2000a, 2000b) developed a modified two-dimensional fluidised bed photocatalytic reactor (FBPR) system and determined the effects of various operating variables on decomposition of mono-nitrogen oxides. FBPR systems have several advantages over conventional immobilised or slurry-type photocatalytic reactors (Lim and Kim, 2002, 2004). The particular photoreactor configuration provides a good exposure of photocatalyst to UV light and good penetration and uniform distribution of the light into the photocatalyst bed that allows more contact between photocatalyst and gas (Lim and Kim, 2004). Furthermore, a newly developed circulating fluidised bed photoreactor system enables remote delivery of UV light to the photocatalyst, which is ideally suited to the gas remediation since it provides good contact between UV light and photocatalyst with reaction gas, higher reactant throughputs, reduced limitations of mass transport (Choi et al., 2001) and lower pressure drops compared to conventional bubbling fluidised beds (Jung et al., 2001; Lim and Kim, 2005).

$\mathrm{TiO}_{2}$ has been used in different forms as a photocatalyst in photocatalytic oxidation reactors (PCO) (Vincent et al., 2007; Moa et al., 2009; An et al., 2012). Photocatalytic reactors can be employed to eliminate pollutants from water and air streams. Coating of $\mathrm{TiO}_{2}$ on walls of the reactor as a thin film, and on the bed particles (silica gel, activated carbon, and alumina), are two common forms of $\mathrm{TiO}_{2}$ use in $\mathrm{PCO}$ reactors. The reactors which use $\mathrm{TiO}_{2}$ coated particles can be categorised into two separate classes: packed and fluidised bed reactors. Since exposure of photocatalyst with UV light and good contact between reactants and photocatalyst are vital factors in the PCO reactions, the fluidised bed reactor is preferred to the packed bed one (Nelson et al., 2007; Dashliborun et al., 2013).

Aims of this study were the design, realisation and test of a fluidised bed photoreactor to decompose ethylene using $\mathrm{TiO}_{2}$ photooxidation activity. Fluidisation tests were performed in order to select the best support for photocatalityc titanium oxide powders, and ethylene photoreduction test was finally carried out using mesoporous mixed $\mathrm{SiO}_{2} / \mathrm{TiO}_{2}$ nanocomposites supported on alumina microspheres.

\section{Materials and methods}

\section{Design of fluidised bed reactor prototype}

In order to design the reactor, several parameters were studied with the aim of maximise the degradation rate of ethylene, such as gas flowrate per unit of reactor volume and/or mass of the catalyst, the geometry of the reactor, and the location of the UV lamps. Figure 1 shows the design and size of the tubular reactor in which the photooxidation of ethylene by titanium oxide-based material, activated by UV light, will take place. The reactor was manufactured in polymethyl methacrylate (commercially known as plexiglass) because of its transparency to light. Internal volume of the cylinder is about $0.9 \mathrm{~L}$. Gas flow of ethylene-contaminated air will cross the reactor containing photocatalytic material.

Piping system and instrumentation diagram is reported in Figure 2.

Major components and features of the reactor are the following:

- Compressor for air circulation (VacuumDesign serie CS, Valmadrera (LC), Italy; nominal flow $7.2 \mathrm{~m}^{3} \mathrm{~h}^{-1}$, pressure 0.8 bar, power $300 \mathrm{~W}$ );

- Flow meter $\left(200 \mathrm{~L} \mathrm{~min}^{-1}\right)$;

- Differential pressure gauge (0-300 mbar);

- Pressure gauge (0-400 mbar);

- UV lamps (Osram FD T26 L18W-73 G13 BLB);

- Gas temperature sensor $\left(0-100^{\circ} \mathrm{C}\right)$;

- Maximum air-flow capacity $\left(80 \mathrm{~L} \mathrm{~min}^{-1}\right)$.

Components, instrumentation and sensors are positioned in the circuit according to Figure 2.

The prototype consists essentially of a tubular reactor, inside of which the titanium dioxide will be fluidised, supported on specific particles with suitable fluidisation behavior, by the introduction of
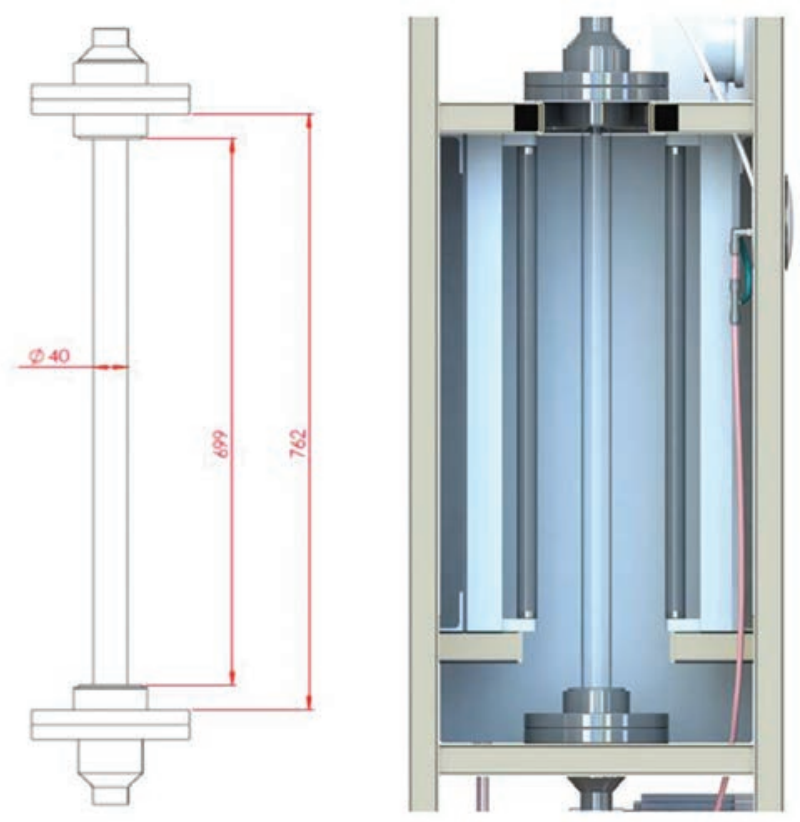

Figure 1. Rendering of the tubular polymethyl methacrylate reactor for photocatalytic oxidation of ethylene (STC s.r.l.). 
gaseous mixture flow. The structure consists of a metal square frame (side $40 \mathrm{~cm}$ ), where the reactor and ultraviolet lamps are located. This part is closed and isolated by means of reflecting panels to minimise the dispersion of the light. Supports for the UV lamps allow movement along the radial direction. The piping and valves are made of rigid PVC. A recirculation circuit is constituted by a pipe that collects the outgoing gas from the flange and conveys it to a compressor, which will impart to the gas the energy to overcome pressure losses due to the fluidised bed and to the recirculation line. Two branches on the discharge line allow the entry of the mixture to be treated and the output of the gas during the washing procedure of the pipes. The return line has a sampling circuit, for gas chromatographic ethylene evaluation. The photocatalytic reactor is equipped with an electrical panel for managing the main utilities. The configuration of the FBP should allow to easily insert an adequate number of UV lamps that produce a uniform and diffuse radiation on active sites of the photocatalyst surface in order to achieve a high mass transfer coefficient between the gas phase and the catalytic surface of the supported $\mathrm{TiO}_{2}$. Both of these aspects (high accessibility to ethylene of catalytically active sites and intense irradiation of the reaction volume) should contribute to increase the efficiency of the reactor compared to other configurations.

\section{Fluidisation tests}

Yang (2003) considered six different fluidisation behaviors for gassolid fluidised beds: fixed bed, bubbling fluidisation, slugging fluidisation, turbulent fluidisation, fast fluidisation, and pneumatic conveying. The slugging regime appears in beds where the bed height $(\mathrm{H})$ over the bed diameter (D) is larger than 2. This ensures that bubbles have the time to coalesce in bigger bubbles (slugs); when the bubbles grow to $2 / 3$ of the bed diameter the system enters to a slugging regime. Furthermore, Crowe (2006) said that turbulent fluidisation occurs when, as the superficial gas velocity increased, a point is reached where the slugs begin to break down. If velocity increases a fast fluidisation regime is then reached. In this regime, solid particles exit from the reactor. Finally, the pneumatic conveying regime is reached when the superficial gas velocity is much higher than the transport velocity; this regime is characterised by the particle being transported out of the bed in a dilute phase. The optimal fluidisation behavior in order to obtain high accessibility to ethylene of catalytically active sites and intense irradiation of the reaction volume results to be the slugging one, providing a good mixing of solid particles and gaseous mixture which passes through, without losses of active material caused by a fast fluidisation behaviour.

Aim of the fluidisation tests was the identification of the best support for titanium dioxide powder, from the point of view of achieving the slugging regime. Fluidisation tests were performed on tabular alumina (dimension range $0.425 \div 1 \mathrm{~mm}$ ); further tests using tabular alumina were performed sieving the material into 3 dimensions intervals: i) nominal size: $0.425 \div 0.85 \mathrm{~mm}$; ii) nominal size: $0.85 \div 0.97 \mathrm{~mm}$; iii) nominal size: $0.97 \div 1 \mathrm{~mm}$ ). The second tested support material consisted of alumina microspheres (dimension range $0.75 \div 1.50 \mathrm{~mm}$ ). Two different size intervals were then tested $(0.75 \div 0.97 \mathrm{~mm}$ and 0.97 $\mathrm{mm} \div 1.5 \mathrm{~mm}$ ). Alumina-based supports were both provided by Salentec s.r.l. (Lecce, Italy). Also glass beads (diameter $5 \mathrm{~mm}$ ) were tested in order to evaluate their fluidisation behavior within the photoreactor prototype.

In order to evaluate the fluidisation behavior of the supports, the tubular reactor was filled with the selected materials and an air flow was flushed within it. The flow was progressively increased in order to monitor the behavior of the fluidised bed from the minimum fluidisation condition up to the pneumatic conveying behavior (Yang, 2003). The achievement of the slugging regime was visually assessed by the operators, and confirmed by the measure of the ratio between the bed height and diameter resulting about $2 / 3$.

Specifically, the attitude of the tested support materials (tabular alumina, alumina microspheres and glass beads) to create a stable fluidised bed without the formation of compact zones which hinder the gas passage, or void volumes, was evaluated, in order to select a material with uniform fluidisation. The best performing material was then selected for the reactor photoactivity evaluation trials (described in paragraph Fluidised bed photoreactor activity evaluation).

\section{Comparison of photocatalytic activity of different materials}

Several $\mathrm{TiO}_{2}$-based materials were tested in order to select the most effective one in terms of ethylene degradation in a known $\mathrm{C}_{2} \mathrm{H}_{4}$-air gaseous mixture.

Photocatalytic material consisted of glass beads (diameter $6 \mathrm{~mm}$ ), previously washed with denatured alcohol and dried in a stove overnight at $105^{\circ} \mathrm{C}$. $\mathrm{TiO}_{2}$ powders were synthesised in aqueous solution by using pluronic F127 $\left(\mathrm{EO}_{106} \mathrm{PO}_{70} \mathrm{EO}_{106}\right)$, a non-ionic triblock copolymer, as a sacrificing template in order to get the ordered mesopores. Total metal oxide content in the solution was maintained to the equivalent amount of $12.256 \mathrm{~g}$. To prepare the solution, firstly $28 \mathrm{~g}$ of F127 (Sigma-Aldrich, St. Louis, MO, USA) was dissolved in $150 \mathrm{~g}$ of water and $600 \mathrm{~g}$ of $2 \mathrm{M} \mathrm{HCl}$ and stirred until it fully dissolved. Then equivalent amount of titanium isopropoxide (Sigma-Aldrich) was dropwise added to the above acidified polymeric aqueous solution. At this moment the precipitate of titanium hydroxides was observed which turned into a clear sol after stirring of about $1 \mathrm{~h}$. Then $8.498 \mathrm{~g}$ of tetraethoxysilane (Sigma-Aldrich) was added dropwise and stirring was continued to another $1 \mathrm{~h}$. Then the obtained solution was placed in a polypropylene bottle with closed cap and heated for $24 \mathrm{~h}$ in an oven at $100^{\circ} \mathrm{C}$ with static condition. After this step a solid product was obtained which was the subjected to heat treatment $550^{\circ} \mathrm{C}$ for $6 \mathrm{~h}$ with the increasing and decreasing ramp of $8 \mathrm{~h}$ to remove the polymer template. After this step pure white powder was obtained. Pure titanium oxide powder, was fixed on the support by immersion in ethanolic suspension of $\mathrm{TiO}_{2}$ $\left(\approx 0.1 \mathrm{gTiO}_{2} / 100 \mathrm{~mL}\right.$ ethanol) (Maneerat et al., 2003) and subsequent drying by evaporation of the solvent at room temperature. The amount

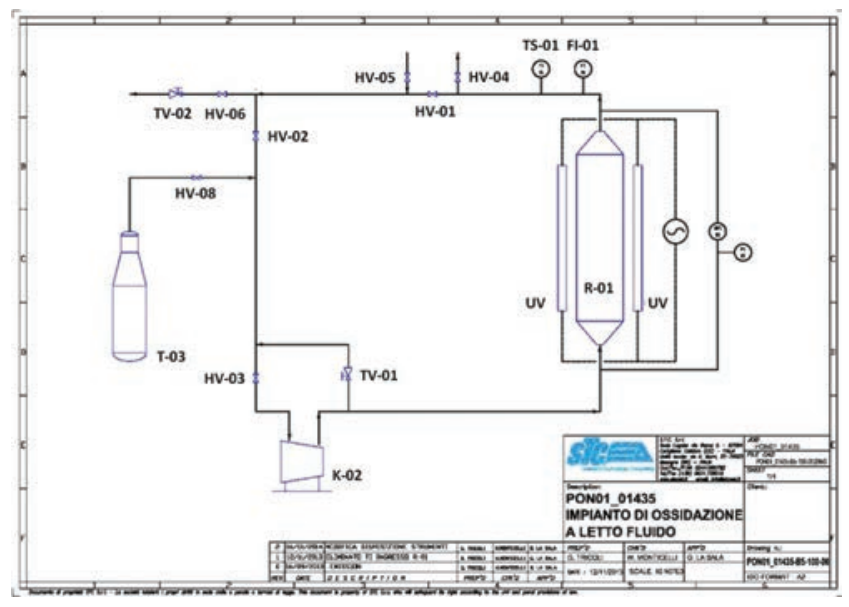

Figure 2. Piping system and instrumentation diagram of fluidised bed photocatalytic reactor (STC s.r.l.). R-01, photocatalytic reactor; T-03, C2H4 cylinder; K-02, compressor; TV 01-TV 02, throttles; HV-01/HV-08, valves; UV, UV lamps supports; FI-01, flow meter; TS-01, temperature sensor. 
of $\mathrm{TiO}_{2}$ powder effectively anchored to the beads was evaluated by the difference in weight of the beads before and after the dipping. Also mesoporous mixed $\mathrm{SiO}_{2} / \mathrm{TiO}_{2}$ nanocomposites with different $\mathrm{TiO}_{2}$ and $\mathrm{SiO}_{2}$ percentage were synthesised as described by de Chiara et al. (unpublished data, 2014) and tested.

Photocatalytic materials were positioned inside glass cylinders (height $=24.5 \mathrm{~cm}$, internal diameter $=4 \mathrm{~cm}$, volume $0.3 \mathrm{~L}$ ) with input and output holes to allow transit of ethylene-enriched air with a flowrate of $2.5 \mathrm{~mL} \mathrm{~min}^{-1}$, while the glass beads was static. The gaseous mixture was obtained diluting ethylene (initial concentration $100 \mathrm{ppm}$ ) with air to obtain the desired final concentration equal to $2 \mathrm{ppm}$. Approximately $300 \mathrm{~mL}$ were flushed within the photocatalytic cylinder during the experiment. The photocatalytic reaction occurred within cold rooms illuminated under black light lamps as UV-A source (OSRAM L18/73 SUPRABLACK ${ }^{\mathrm{TM}}$, UV-A: 400-315 nm). The light intensity was measured with a digital luxmeter (ASITA LX350).

\section{Fluidised bed photoreactor activity evaluation}

Mixed $\mathrm{SiO}_{2} / \mathrm{TiO}_{2}$-coated alumina microspheres with high porosity were developed and tested within the FBP. Following, the coating process carried out by the Department of Engineering of University of Salento (Lecce, Italy) is described. Ethanolic sol containing T-SBA 73 photocatalytic nanocomposites (composed of $70 \% \mathrm{TiO}_{2}$ and $30 \% \mathrm{SiO}_{2}$ ) was used to coat alumina beads in a desiccator under vacuum. After coating, the beads were annealed at $550^{\circ} \mathrm{C}$ for $1 \mathrm{~h}$.

Tests were carried out in order to verify FBP functioning and the photocatalytic activity of the developed material.

The photoreactor can be used in different action modes. Following, the steps to test the performance of the photoreactor with known concentration of ethylene mixture from gas cylinder (T-03) are reported. The compressor capacity will allow the gaseous mixture to drain from the tank or from the external atmosphere. The prototypal system is designed to work in continuous or batch mode. The throttle TV-01 allows reaching the optimal condition of the fluidised bed in the reactor. The flow meter provides the measurement of the flow actually circulating in the reactor. To start the reaction, it is sufficient to turn on the UV lamps. The degree of ethylene conversion can be varied increas- ing or decreasing the contact time between pollutant and photocatalytic surface (progressively closing or opening TV-02). In order to operate in batch mode, it is sufficient to close the exit valve before turning on the UV lamp. The system will lead to a pressure equal to the discharge pressure of the cylinder.

The material was inserted in the tubular reactor inside the FBP and the system was used in batch mode in order to allow the continuous recirculation of the ethylene-enriched gaseous mixture with a total flow of $80 \mathrm{~L} \mathrm{~min}^{-1}$ and a pressure of 0.1 bar. Approximately $360 \mathrm{~g}$ of coated material were inserted in the plexiglass reactor. To evaluate the FBP photocatalytic activity in decomposing ethylene, exogenous ethylene was diluted within the air present in the system (approximately 3 L) to reach the desired initial concentration ( $40 \mathrm{ppm})$. After closing the system, $3 \mathrm{~L}$ of $\mathrm{C}_{2} \mathrm{H}_{4}$-enriched air re-circulated within the photoreactor. Gaseous mixture was then treated by means of re-circulating system under UV illumination up to $3 \mathrm{~h}$. The catalytic efficiency of the photoreactor was monitored following ethylene concentration and its reduction percentage during the reaction time.

\section{Ethylene detection}

The detection of the concentrations of ethylene was performed through a gas chromatograph Agilent, model $7890 \mathrm{~A}$, with a flame ionisation detector, with a limit of detection below $0.01 \mathrm{ppm}$. Detector temperature was set at $300^{\circ} \mathrm{C}$, with hydrogen flow of $45 \mathrm{~mL} \mathrm{~min}^{-1}$ and air flow of $400 \mathrm{~mL} \mathrm{~min}^{-1}$. For the separation of ethylene a metal packed column 13073-U (Supelco, Bellefonte, PA, USA) was used. Helium was used as carrier gas. Oven temperature was set at $120^{\circ} \mathrm{C}$.

\section{Results}

\section{Realisation of fluidised bed reactor prototype}

Some images of the reactor are shown in Figure 3. Generally, fluidisation occurs when solid microparticles are suspended in an upwardflowing stream of fluid. Reactions in fluidised beds are described by the Kunii-Levenspiel bubbling-bed model. As the reactant gases form
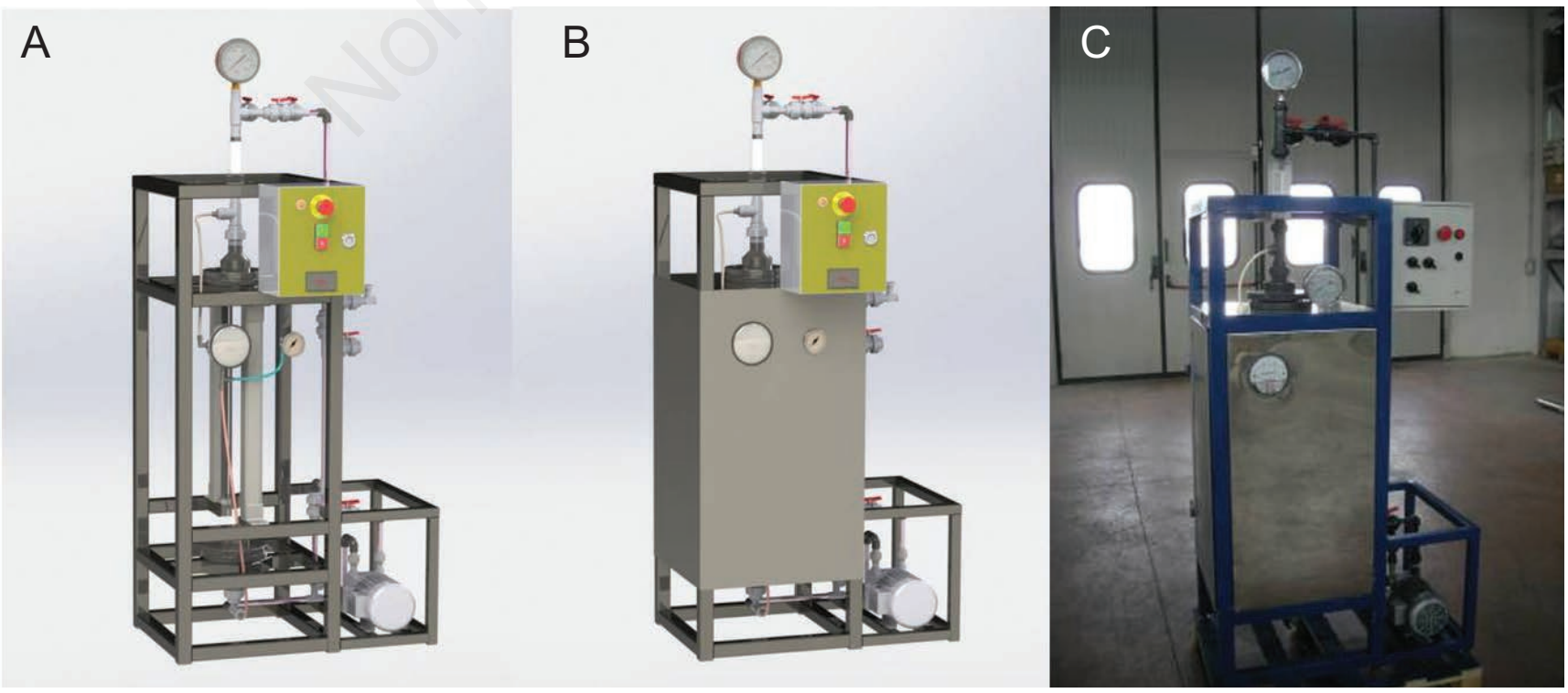

Figure 3. Computer rendering (A and B) and a photo (C) of the fluidised bed photocatalytic reactor prototype (STC s.r.l.). 
ascending bubbles, mass transfer takes place as they flow in and out the mass of solid particles, thus enhancing the photocatalytic reaction. The rate at which the reactants and products transfer in and out of the bubble affects the conversion, as does the time it takes for the bubble to pass through the bed (Fogler and Gürmen, 2008).

\section{Fluidisation tests}

The first fluidisation test was conducted on samples of tabular alumina. As the superficial gas velocity increases, the system reaches the bubbling fluidisation regime. In this regime, bubbles start to form and combine causing solid mixing; the velocity at which bubbles appeared is known as the minimum bubbling velocity. Within the fluidised bed, using tabular alumina sample, compact zones occurred due to the irregularity of the microparticles, which hinder the gas passage. Because of this difficulty encountered by the gas, multiple beds were created. The beds ascended along the tube, collapsing when the gas pressure was no longer efficient to their sustenance. This type of fluidised bed was unstable; however, maintaining a constant flow rate of the inlet gas, the described phenomenon was attenuated, and disappeared when the redistribution of void volumes allowed a more uniform fluidisation. Consequently, after a first phase of particles mixing, FBP could work in minimum fluidisation conditions. On the other hand, because of the morphology of the tabular grains, a minimum change of void volume level caused the return to the previous behavior. A solution to this multiple behavior of the fluidised bed could be represented by using a more uniform material. To this aim, the tabular alumina was sieved into 3 size intervals as defined in Materials and Methods section. The first size interval $(0.425 \div 0.85)$ was not tested given its high degree of heterogeneity and the small dimension of its particles that made it not suitable for fluidisation. In further tests, using the second and the third size intervals, it was possible to fluidise the material. Creation of multiple bed still occurred, although in a less accentuated way. It was concluded that tabular alumina is not suitable as support for titanium oxide powders, given the irregularities in the size and the tendency to create multiple beds with non-uniform behavior. To allow the maximum contact between photocatalyst and ethylene, it is necessary that the fluid bed remains the most stable and uniform as possible. Alumina microspheres, whose diameter ranged between 0.75 and $1.5 \mathrm{~mm}$, were used for further trials, due to their more regular shape than tabular support. A minimum of $100 \mathrm{~g}$ of material were necessary in order to get the minimum fluidisation, and the corresponding flow was about $40 \mathrm{~L}$ $\min ^{-1}$. In these conditions the measured pressure drops were low. Increasing the quantity of microspheres inside the reactor up to $1.8 \mathrm{~kg}$ and maintaining a constant input flow rate, the pressure losses increased. Increasing the flow rate, pressure losses did not increase and the bed maintained the minimum fluidisation condition. Due to the dispersed particle size, it was possible to observe that the void volume degree inside the bed was not uniform, and zones with different permeability characteristics occurred. This could affect the efficiency of the reactor, shielding the inner portions of the bed from UV light. Furthermore, it was clear from this test that the particle size of the material should be as least dispersed as possible in order to obtain uniform void volume degree and avoid occurrence of multiple beds when the minimum fluidisation condition was respected. After sieving the microspheres into 2 dimensional intervals (as reported in paragraph Fluidisation tests) further tests were performed. The fluidisation behavior of the two samples was substantially similar. The difference between the two beds was the void volume degree: material with diameters ranging from $0.97 \mathrm{~mm}$ to $1.5 \mathrm{~mm}$, showed a greater degree of voids than those ranging from 0.75 to $0.97 \mathrm{~mm}$ of diameter and this could represent an advantage for the optimal diffusion and distribution of ultraviolet light.
Tests on glass beads were also carried out. In this case the fluidisation occurred with regular behavior and no phenomena of redistribution of the voids were observed. Moreover the flow through the bed was uniform, without creating preferential channels for air passage. These characteristics are due to the high regularity of the particle size. This type of media, like the alumina microspheres, may be the most indicated for use in fluidised bed photoreactors. However, $\mathrm{TiO}_{2}$-coated glass beads showed no ethylene reduction activity in preliminary tests previously performed (as described in paragraph Comparison of photocatalytic activity).

From the results described above alumina microspheres were finally chosen as support material for titanium oxide powders to be used in the FBP, both for their fluidisation performance and for their ability to incorporate photocatalytic material. The microparticle cavities were coated with mesoporous mixed $\mathrm{SiO}_{2} / \mathrm{TiO}_{2}$ nanocomposite material (TSBA 73) as previously described. The photocatalytic material showed a slugging fluidisation behavior that allowed high contact time with ethylene and uniform irradiation by UV lamps.

\section{Comparison of photocatalytic activity}

$\mathrm{TiO}_{2}$ microspheres, usually possess a high specific surface area and a high pore volume size, and these properties increase the accessible surface area and the rate of mass transfer for pollutant adsorption, resulting in better photocatalytic performance (Li et al., 2007; Zheng et al., 2009, 2010; Liu et al., 2010a, 2010b; Xiang et al., 2011). The white photocatalytic powder obtained as described in Materials and methods section (in paragraph Fluidisation tests) was previously positioned on different support, in order to characterise the most efficient one and easily manage it.

In the first phase titanium oxide was fixed on $6 \mathrm{~mm}$ diameter glass beads, as described in the Materials and methods section. The obtained outside layer was of $0.00037 \mathrm{mg}_{\mathrm{Ti} 2} / \mathrm{mm}^{2}$. To verify the quality of titanium oxide coating on glass beads different images were acquired. After dipping in ethanolic suspension the beads were photographed at different levels of enlargement (Figure 4). The picture shows how the thin layer of $\mathrm{TiO}_{2}$ powder is not regular and uniform on the whole surface of the glass marbles. Black spots in the picture (more evident in $100 \mathrm{X}$ enlargement), correspond to titanium oxide microparticles.

Experimental evidence, reported in Figure 5, did not show any reduction of ethylene between cylinder input and output using titanium oxide-coated glass beads, if compared with the ethylene reduction obtained with T-SBA powder. The $\mathrm{TiO}_{2}$-coated glass beads used in these trials were not effective in reducing ethylene in gaseous mixture, probably because of the low efficiency of coating techniques. As previously showed in the coated-support image, small quantities of $\mathrm{TiO}_{2}$ powder were attached on the support, due to its spherical surface. Instead, using as photocatalytic material 0.5 grams of nanocomposite powder composed by $70 \% \mathrm{TiO}_{2}$ and $30 \% \mathrm{SiO}_{2}$ it was possible to observe a high ethylene reduction percentage: after $2 \mathrm{~h}$ about $70 \%$ of the initial $\mathrm{C}_{2} \mathrm{H}_{4}$ was removed from the atmosphere using a flow-through system. The same results were obtained during further trials using T-SBA in flowthrough and closed system comparing the effect obtained with and without ultraviolet light (data not shown). In the light-exposed sample the reduction of ethylene was due to the synergistic effect of photooxidation given by $\mathrm{TiO}_{2}$ and adsorbtion given by the silica present in the sample. $\mathrm{SiO}_{2}$ is able to enhance the photocatalytic activity of titanium oxide. On the basis of these results the latter material was selected and tested in the fluidised bed photoreactor.

\section{Preliminary fluidised bed photoreactor activity evaluation}

In a preliminary test performed in order to evaluate photocatalytic activity of the reactor it was observed a consistent reduction of ethyl- 


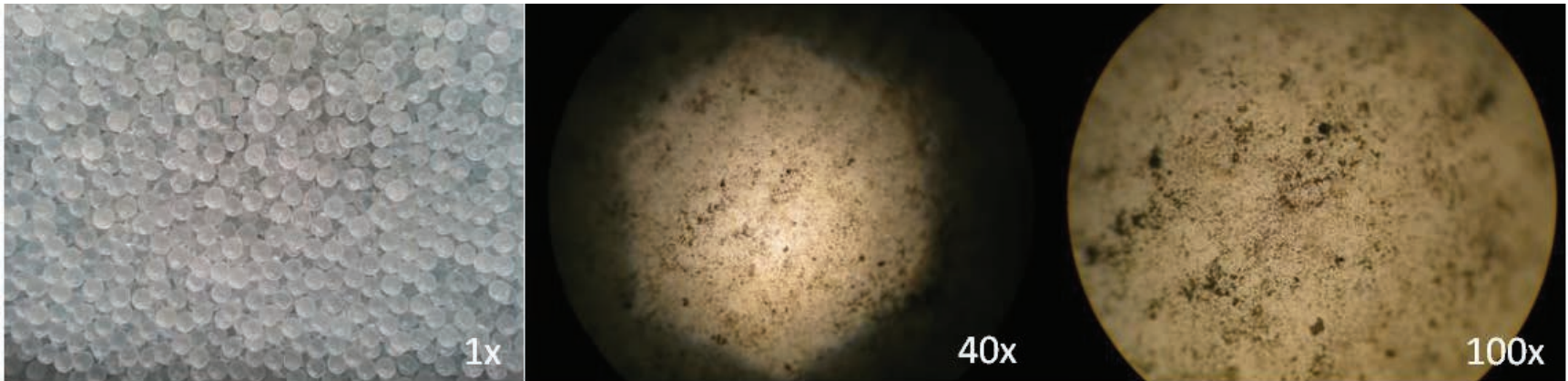

Figure 4. Photocatalytic material at different levels of enlargement.

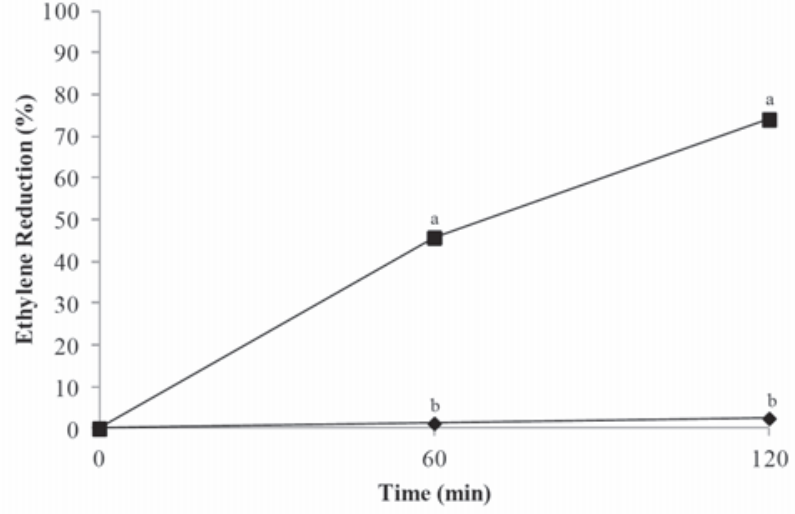

Figure 5. The graph reports the reduction percentage over time under UV illumination, (light intensity 80 lux, $4 \mathrm{X}$ 18W-lamps). Reactor volume about $0.3 \mathrm{~L}$. Photocatalytic material: TiO2-coated glass beads $\left(0.00037 \mathrm{mgTiO} / \mathrm{mm}^{2}\right.$ of glass beads) ( $)$, and TSBA $73\left(0.5 \mathrm{~g}\right.$ of active material into the reactor) $(\square) ; \mathrm{C}_{2} \mathrm{H}_{4}$ concentration of the treated gaseous mixture: $2 \mathrm{ppm}$; flow rate of C2H4-enriched gaseous mixture: $2.5 \mathrm{~mL} \mathrm{~min}^{-1}$. Reported values are means of three replicates for each sampling time. Means with different letters are significantly different according to the Tukey's test $(P$-value $\leq 0.05)$.

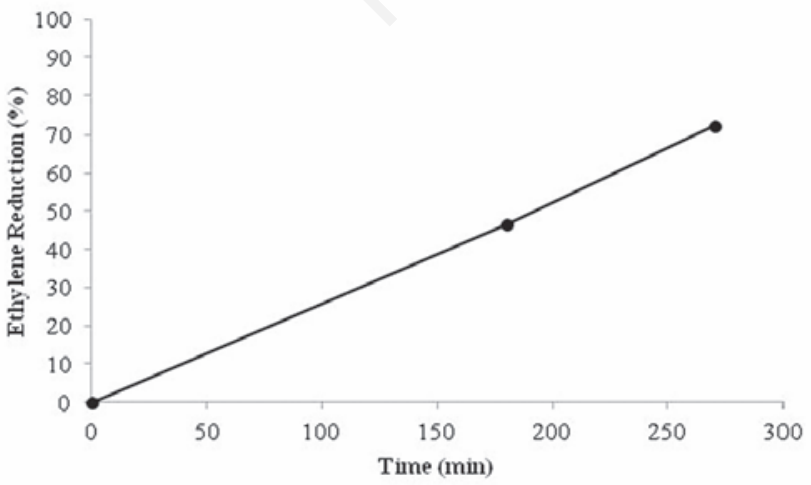

Figure 6. Rate of ethylene reduction percentage in the gaseous mixture within the fluidised bed photoreactor under UV light exposure. Light intensity 40 lux ( 2 X 18W-lamps), C2H4 concentration of the treated gaseous mixture: $40 \mathrm{ppm}$, re-circulating volume approximately $3 \mathrm{~L}$, reactor volume about $0.9 \mathrm{~L}$. ene concentration after $3 \mathrm{~h}$ of treatment under UV light (two 18W black light lamps, approximately 40 lux) (47\%). At the end of the experiment, after $270 \mathrm{~min}$, it was possible to reach $11.3 \mathrm{ppm}$, with a maximum reduction percentage of about $72.5 \%$ (Figure 6 ), starting from an ethylene concentration of $40 \mathrm{ppm}$. The prototype of FBP resulted to be worthy of further investigation in order to improve photocatalytic material performances, and be used inside storage room to reduce ethylene concentration.

However, collisions caused by fluidisation regime among the microparticles caused a tendency of the coated powdered photocatalytic material to separate from its support. As a consequence of this, the powdered coating material tended to block reactor higher and lower filters with a progressive reduction of the flow rate and of the bed height, potentially reducing FBP efficacy. A more efficient and stable coating process is necessary, in order to make the photocatlytic material suitable for the use within the fluidised bed photoreactor without losses of photoactive coating.

\section{Conclusions}

After the realisation of a photoreactor prototype for the decomposition of ethylene under UV illumination, fluidisation and photocatalytic tests on different materials were carried out. Tabular alumina resulted to be not suitable for use as support for titanium oxide in fluidised bed, because of its multiple bed creation and poor propensity for fluidisation. Glass beads showed a good fluidisation behavior, however, it was demonstrated that they were not active in decomposing ethylene. A good choice seemed to be alumina microspheres that showed good fluidisation properties and might be suitable for use as support for photocatalytic materials. Using porous alumina microspheres as support and nanocomposite powder T-SBA 73 as photocatalytic coating it was possible to reach a maximum reduction percentage of about $72 \%$ after $4.5 \mathrm{~h}$ under UV light. It was possible to notice, however, that the fluidisation regime caused strong collisions between the coated microspheres. In order to carry out further, more exhaustive experiments using the FBP there is a need to develop active photocatalytic material with suitable fluidisation properties and minimal loss of active powder. The development of materials with high photocatalytic activity to be used in photoreactors may lead to the replacement of traditional, discontinuous and/or expensive techniques for removal or inhibition of ethylene action during postharvest storage.

With the completion of FBP operation, its use will be useful for the companies to avoid the detrimental effects ethylene-related on fresh plant tissues. The technological transfer to the postharvest industry 
could be then carried out, with many advantages in terms of prolonging fresh produce shelf life, and reducing losses.

\section{References}

Akiyama S., Togeda H. 2000. Hikari shokubai to kanrengijutsu: 21 seikikigyo no technology. Nikkankogyo Shimbunsha, Tokyo, Japan.

An T., Chen J., Nie X., Li G., Zhang H., Liu X., Zhao H. 2012. Synthesis of carbon nanotube-anatase $\mathrm{TiO}_{2}$ sub-micrometer-sized sphere composite photocatalyst for synergistic degradation of gaseous styrene. ACS Appl. Mater. Inter. 4:5988-96.

Augugliaro V., Bellardita M., Loddo V., Palmisano G., Palmisano L., Yurdakal S. 2012. Overview on oxidation mechanisms of organic compounds by $\mathrm{TiO}_{2}$ in heterogeneous photocatalysis. J. Photochem. Photobiol. C 13:224-45.

Augugliaro V., Litter M., Palmisano L., Soria J. 2006. The combination of heterogeneous photocatalysis with chemical and physical operations: a tool for improving the photoprocess performance. J. Photochem. Photobiol. C 7:127-44.

Baek M.-H., Yoon J.-W., Hong J.-S., Suh J.-K. 2013. Application of $\mathrm{TiO}_{2}$-containing mesoporous spherical activated carbon in a fluidised bed photoreactor - Adsorption and photocatalytic activity. Appl. Catal. A 450: 222-9.

Choi W.Y., Ko J.Y., Park H.W., Chung J.S. 2001. Investigation on $\mathrm{TiO}_{2}$-coated optical fibers for gas-phase photocatalytic oxidation of acetone. Appl. Catal. B 31:209-20.

Crowe C.T. 2006. Multiphase flow handbook. CRC Press, Boca Raton, FL, USA.

Dashliborun A.M., Sotudeh-Gharebagh R., Hajaghazadeh M., Kakooei H., Afshar S. 2013. Modeling of the photocatalytic degradation of methyl ethyl ketone in a fluidised bed reactor of nano-TiO2/ $-\mathrm{Al}_{2} \mathrm{O}_{3}$ particles. Chem. Eng. J. 226:59-67.

Dibble L.A., Raupp G.B. 1992. Fluidised-bed photocatalytic oxidation of trichloroethylene in contaminated air streams. Environ. Sci. Technol. 26:492-45.

Fogler H.S. and Gürmen M.N. 2008. Diffusion and reaction in porous catalysts. Professional reference shelf. Fogler \& Gurmen ${ }^{\odot}$ - University of Michigan. Available from: http//www.umich.edu/ elements/12chap/ html/12prof2a.htm

Garcia-Lopez E., Marci G., Serpone N., Hidaka H. 2007. Photoassisted oxidation of the recalcitrant cyanuric acid substrate in aqueous $\mathrm{ZnO}$ suspensions. J. Phys. Chem. C 111:18025-32.

Gulyas H., Bockelmann D., Hemmerling L., Bahnemann D., Sekoulov I. 1994. Treatment of recalcitrant organic compounds in oil reclaiming wastewater by ozone/hydrogen peroxide and UV/titanium dioxide. Water Sci. Technol. 29:129-32.

Hoffmann M.R., Martin S.T., Choi W., Bahnemann D.W. 1995. Environmental applications of semiconductor photocatalysis. Chem. Rev. 95:69-96.

Ilkenhans T., Poulston S., Rowsell L., Smith A.W.J., Terry L.A. 2007. Development of a new Palladium-based ethylene scavenger. In: Ramina A. et al. (eds), Advances in plant ethylene research Proc. 7th International Symp. on the Plant Hormone Ethylene. Springer, Amsterdam, the Netherlands, pp 211-214.

Imoberdorf G.E., Taghipour F., Keshmiri M., Mohseni M. 2008. Predictive radiation fieldmodeling for fluidised bed photocatalytic reactors. Chem. Eng. Sci. 63:4228-38.

Jung S.H., Park S.H., Lee D.H., Kim S.D. 2001. Surface modification of HDPE powders by oxygen plasma in a circulating fluidised bed reactor.
Poly. Bull. 47:199-205.

Li H., Bian Z., Zhu J., Zhang D., Li G., Huo Y., Li H., Lu Y. 2007. Mesoporous titania spheres with tunable chamber stucture and enhanced photocatalytic activity. J. Am. Chem. Soc. 129:8406-7.

Lim T.H., Jeong S.M., Kim S.D., Gyenis J. 2000a. Degradation characteristics of $\mathrm{NO}$ by photocatalysis with $\mathrm{TiO}_{2}$ and $\mathrm{CuO} / \mathrm{TiO}_{2}$. React. Kinet. Catal. Lett. 71:223-29.

Lim T.H., Jeong S.M., Kim S.D., Gyenis J. 2000b. Photocatalytic decomposition of $\mathrm{NO}$ with $\mathrm{TiO}_{2}$ particles. J. Photochem. Photobiol. A 134:209-17.

Lim T.H., Kim S.D. 2002. Photocatalytic degradation of trichloroethylene over $\mathrm{TiO}_{2} / \mathrm{SiO}_{2}$ in an annulus fluidised bed reactor. Korean J. Chem. Eng. 19:1072-7.

Lim T.H., Kim S.D. 2004. Trichloroethylene (TCE) degradation by photocatalysis in annular flow and annulus fluidised bed photoreactors. Chemosphere 54:305-11.

Lim T.H., Kim S.D. 2005. Photocatalytic degradation of trichloroethylene (TCE) over $\mathrm{TiO}_{2} /$ silica gel in a circulating fluidised bed (CFB) photoreactor. Chem. Eng. Process. 44:327-34.

Liu M., Piao L., Lu W., Ju S., Zhao L., Zhou C., Li H., Wang W. 2010a. Flowerlike $\mathrm{TiO}_{2}$ nanostructures with exposed $\{001\}$ facets: facile synthesis and enhanced photocatalysis. Nanoscale 2:1115-7.

Liu S., Yu J., Jaroniec M. 2010b. Tunable photocatalytic selectivity of hollow $\mathrm{TiO}_{2}$ microspheres composed of anatase polyhedra with exposed $\{001\}$ facets. J. Am. Chem. Soc. 132:11914-6.

Maneerat C., Hayata Y., Egashira N., Sakamoto K., Hamai Z., Kuroyanagi M. 2003. Photocatalytic reaction of $\mathrm{TiO}_{2}$ to decompose ethylene in fruit and vegetable storage. Trans. ASABE 46:725-30.

Moa J., Zhang Y., Xu Q., Lamson J.J., Zhao R. 2009. Photocatalytic purification of volatile organic compounds in indoor air: a literature review. Atmos. Environ. 43:2229-46.

Nelson R.J., Flakker C.L., Muggli D.S. 2007. Photocatalytic oxidation of methanol using titania-based fluidised beds. Appl. Catal. B 69:189-95.

Saltveit M.E. 1999. Effect of ethylene on quality of fresh fruits and vegetables. Postharvest Biol. Tec. 15: 279-92.

Smith A.W.J., Poulston S., Rowsell L., Terry L.A., Anderson J.A. 2009. A new palladium-based ethylene scavenger to control ethylene-induced ripening of climacteric fruit. Platinum Met. Rev. 53:112-22.

Vega A.A., Imoberdorf G.E., Mohseni M. 2011. Photocatalytic degradation of 2,4-dichlorophenoxyacetic acid in a fluidised bed photoreactor with composite template-free $\mathrm{TiO}_{2}$ photocatalyst. Appl. Catal. A 405:120-8.

Vincent G., Queffeulou A., Marquaire P., Zahraa 0. 2007. Remediation of olfactory pollution by photocatalytic degradation process: study of methyl ethyl ketone (MEK). J. Photochem. Photobiol. A 191:42-50.

Watanabe N., Horikoshi S., Hidaka H., Serpone N. 2005. On the recalcitrant nature of the triazinic ring species, cyanuric acid, to degradation in Fenton solutions and in UV-illuminated $\mathrm{TiO}_{2}$ (naked) and fluorinated $\mathrm{TiO}_{2}$ aqueous dispersions. J. Photochem. Photobiol. A 174:229-38.

Xiang Q., Yu J., Jaroniec M. 2011. Tunable photocatalytic selectivity of $\mathrm{TiO}_{2}$ films consisted of flower-like microspheres with exposed $\{001\}$ facets. Chem. Commun. 47:4532-4.

Yang W.C. (Ed.). 2003. Handbook of fluidisation and fluid-particle systems. CRC Press, Boca Raton, FL, USA.

Yue P.L., Khan F. 1983. Photocatalytic ammonia synthesis in a fluidised bed reactor. Chem. Sci. Eng. 38:1893-900.

Zheng Z., Huang B., Qin X., Zhang X., Dai Y. 2010. Strategic synthesis of hierarchical $\mathrm{TiO}_{2}$ microspheres with enhanced photocatalytic activity. Chem. Eur. J. 16:11266-70.

Zheng Z., Huang B., Qin X., Zhang X., Dai Y., Jiang M., Wang P., Whangbo M.-H. 2009. Highly efficient photocatalyst: $\mathrm{TiO}_{2}$ microspheres produced from $\mathrm{TiO}_{2}$ nanosheets with a high percentage of reactive $\{001\}$ facets. Chem. Eur. J. 15:12576-9. 